\title{
PERANCANGAN BUKU CERITA BERGAMBAR NYI RORO KIDUL SANG LEGENDA LAUT SELATAN
}

\author{
Diah Ayu Mustika ${ }^{1)}$, Nada Shofura Syarifah ${ }^{2)}$ \\ Program Studi Desain Komunikasi Visual, \\ Fakultas Bahasa dan Seni, Universitas Indraprasta PGRI \\ Jl. Nangka No. 58 C, Tanjung Barat, Jakarta Selatan, 12530, Indonesia \\ dyahayu694@gmail.com
}

\begin{abstract}
Abstrak
Nyi Roro Kidul adalah legenda rakyat yang sangat terkenal pada masyarakat Pulau Jawa. Orangorang di sepanjang pantai selatan pulau Jawa meyakini mitos tentang karakter legendaris ini sebagai wanita berparas cantik dan supranatural yang memiliki otoritas alam setan di Samudera Indonesia (Samudra Hindia) atau Segoro Kidul (Laut Selatan). Tujuan penelitian ini dibuat untuk memperkenalkan kepada anak-anak tentang bagaimana sejarah Nyi Roro Kidul melalui desain buku cerita bergambar. Metode yang digunakan dalam penelitian ini kualitatif berdasarkan referensi jurnal dan artikel sebagai patokan dalam penelitian ini. Buku ini memiliki desain perancangan dengan menggambarkan sosok Nyi Roro Kidul secara menarik dan ringan, menggambar latar-latar tempat yang beraneka ragam, sehingga membuat buku ini lebih mengesankan. Dengan desain yang modern dan warna yang menarik diharapkan anak-anak menyukai dan tertarik untuk membaca buku tersebut.
\end{abstract}

Kata Kunci: Nyi Roro Kidul, Pantai Selatan, Kepercayaan, Desain

\begin{abstract}
Nyi Roro Kidul is a popular legend of the people of Java Island. People along the south coast of Java believe the myth about this legendary character as a beautiful and supernatural woman who has the devil Nature Authority in the Ocean of Indonesia (Indian Ocean) or Segoro Kidul (South Sea). The purpose of this research was made to introduce children about the history of Nyi Roro Kidul through picture book design. The methods used in this research are qualitative based on journal and article references as a benchmark in this study. The book has a designing design by portraying the figure of Nyi Roro Kidul is a compelling and lightweight, drawing of diverse backgrounds, making this book more impressive. With a modern design and interesting colors, it is expected that children love and are interested in reading the book.
\end{abstract}

Keywords: Nyi Roro Kidul, South Beach, trust, design

Correspondence author: Nada Shofura,nadashofura25@gmail.com, Jakarta, and Indonesia

This work is licensed under a $C C-B Y-N C$ 


\section{PENDAHULUAN}

"Ratu Kidul" merupakan sosok penguasa Pantai Selatan yang dikenal dengan sebutan Kanjeng Ratu Kidul atau Nyi Roro Kidul. Ia merupakan dewi penjaga Laut Selatan dan penguasa Laut Selatan. Cerita lisan Nyi Roro Kidul sampai saat ini masih sering diperbincangkan, baik oleh yang mempercayai keberadaannya sampai yang tidak mempercayainya. Di kalangan masyarakat Jawa, Nyi Roro Kidul merupakan sebuah mitos yang terkenal, dan masih terasa hingga kini dalam kehidupan masyarakat Jawa. Mitos ini merupakan sebuah tradisi yang masih bertahan. Ceritanya sampai sekarang tetap terjaga di Keraton Yogyakarta karena mempunyai peran dan pengaruh yang sangat besar dalam sejarah berdirinya kerajaan Mataram sebagai simbol kekuasaan dalam legitimasi politik Jawa.

Pada masyarakat yang tinggal di pesisir Pantai Selatan, seperti halnya daerah pantai Parangkusumo setiap tahunnya selalu diadakan upacara" Labuhan" yang banyak didatangi para peziarah yang ingin mendapatkan berkah dari Nyi Roro Kidul. Lain halnya pada masyarakat Sunda Jawa Barat, cerita Nyi Roro Kidul tidak memiliki pengaruh terhadap tata kehidupan masyarakat pada umumnya, juga tidak ditempatkan sebagai unsur pembentuk negara yang memiliki kepentingan terhadap tatanan politik pemerintahan. Namun, bagi sebagian masyarakat Jawa Barat yang berada di daerah Pangandaran dan Pelabuhan Ratu, cerita ini besar sekali pengaruhnya terhadap pola kehidupan bermasyarakat. Mereka sangat meyakini keberadaan Nyi Roro Kidul sebagai penguasa Laut Selatan. Ini terbukti dari diadakannya upacara ritual tahunan yang dikenal dengan sebutan hajat laut di daerah Pangandaran hal ini dilakukan untuk menghormati keberadaan penguasa Pantai Selatan. (Jurnal al-Tsaqafa Volume 13;2016, No 2). Mitos Nyi Roro Kidul sebagai penguasa pantai selatan Pulau Jawa memiliki berbagai macam perbedaan pandangan dunia, agama, logika dan kepercayaan. Bisa dikatakan demikian karena menurut pandangan logika bahwa segala bentuk gaib sebenarnya merupakan kumpulan energi yang terjadi pada beberapa tempat tertentu serta memancarkan kekuatan untuk membangkitkan sesuatu objek. Agama (Islam) memang menyebutkan bahwa ada dunia jin yang mendampingi dunia manusia. Pengertian mendampingi dapat berarti membantu atau mengganggu manusia. Hampir sama halnya dengan pandangan agama, kepercayaan yang kerap dikaitkan dengan mitos memandang bahwa dunia gaib itu juga ada dan memiliki pengaruh sangat besar dalam kehidupan manusia baik dalam lingkungan keseharian, pekerjaan, ataupun keimanan. Perbedaan dengan pandangan agama bahwa terdapat banyak variasi mahluk halus dalam dunia kepercayaan disertai dengan istilah berbeda karena disesuaikan dengan kondisi kebahasaan masyarakat setempat. Percaya atau rasa ingin tahu terhadap dunia mahluk halus tergantung dari kondisi pemikiran manusia. Namun, rasa keingintahuan menjadi faktor utama yang menggugah rasa seseorang untuk menguak tabir yang selama ini masih menutupi apa dibalik kejadian atau gejala alam di sekitar lingkungan mereka. Bencana alam, kurang beruntung, ingin sukses, dan sebagainya adalah bagian dari kehidupan manusia. Penggunaan metode logika seringkali terbentur pada kesulitan melaksanakan proses untuk mengubah sesuatu menjadi lebih baik, aman, dan sukses. Metode supranatural adalah cara yang dianggap mumpuni dan cukup mudah dilakukan untuk mencapai tujuan tersebut. Dengan melakukan proses ritual tertentu, sebagian masyarakat merasa mendapat perlindungan dari penguasa gaib wilayah mereka. (Irvan Setiawan,2009 188-189)

Penelitian yang berjudul perancangan Buku Cerita Bergambar tentang Nyi Roro Kidul Sang Legenda Laut Selatan, tujuan penelitian ini dibuat untuk memperkenalkan kepada anakanak tentang bagaimana sejarah Nyi Roro Kidul melalui desain buku cerita bergambar.

Buku bergambar adalah buku cerita yang disajikan dengan menggunakan teks dan ilustrasi atau gambar. Buku ini biasanya ditujukan pada anak-anak. Untuk anak usia sekolah dasar kelas rendah, gambar berperan penting dalam proses belajar membaca dan menulis. Buku bergambar lebih memotivasi mereka untuk belajar. Dengan buku bergambar yang baik, anak-anak akan terbantu dalam proses memahami dan memperkaya pengalaman dari cerita (Rothlein, 1991)

Gambar dalam cerita anak-anak harus sesuai dengan tema, latar, perwatakan dan plot dalam cerita (Stewing, 1980). Begitu pula sebagai ilustrasi dalam buku cerita bergambar (pictury story book) berfungsi untuk mengilustrasikan pelaku, latar, dan kegiatan yang dipakai untuk 
membangun rangkaian cerita (plot) dari suatu cerita. Buku bergambar yang bagus dapat memberi anak kesenangan/hiburan dan pengalaman estetik.

Melalui perancangan buku cerita bergambar tentang Nyi Roro Kidul sang penguasa lautan ini, diharapkan bisa menjadi sumber pengetahuan bagi para pembacanya, khususnya anak-anak.

\section{Buku Cerita Bergambar}

Buku cerita bergambar memuat pesan melalui ilustrasi dan teks tertulis. Kedua elemen ini merupakan elemen penting pada cerita. Buku-buku ini memuat berbagai tema yang sering didasarkan pada pengalaman kehidupan sehari-hari anak. Karakter dalam buku ini dapat berupa manusia atau binatang. Di sini ditampilkan kualitas manusia, karakter, dan kebutuhan, sehingga anak-anak dapat memahami dan menghubungkannya dengan pengalaman pribadinya. Buku cerita yang diilustrasikan dan ditulis dengan baik akan memberikan kontribusi pada perkembangan sastra anak. Buku bergambar yang baik memuat elemen intrinsik sastra, seperti alur, struktur yang baik, karakter yang baik, perubahan gaya, latar, dan tema yang menarik. Buku ini dapat menimbulkan imajinasi orisinal dan mempersiapkan stimulus berpikir kreatif. Buku cerita bergambar dapat memberikan apresiasi bahasa dan mengembangkan komunikasi lisan, mengembangkan proses berpikir kognitif, ungkapan perasaan, dan meningkatkan kepekaan seni. Jenis-jenis buku bergambar yang telah diuraikan di atas dapat memberikan pesan-pesan khusus bagi anak untuk memahami unsur-unsur dalam cerita. Contoh buku cerita bergambar : Si Kancil Anak Nakal (Mencemooh sang raja), Langit Akan Runtuh (memperdaya gajah), Bertemu Buaya (terhindar jadi mangsa), Kena batunya (lomba cepat), Kue Benggala (monyet-monyet makin marah), Ikat Pinggang Kebesaran (harimau tertipu), Bakal jadi Santapan (mencuri mentimun, Si Kancil Sadar (mimpi yang indah), Kera dan Penyu, Sepatu baru dan Miki Tikus Piknik. (Rothlein dan Meinbach,1991)

\section{Layout}

Layout adalah pengaturan yang dilakukan dalam mempromosikan seluruh elemen desain untuk menghasilkan bentuk grafis yang diinginkan. Menurut Smith (1985) dalam Sutoppo (2002:174) mengatakan bahwa proses mengatur hal atau pembuatan Layout adalah merangkaikan unsur tertentu menjadi susunan yang baik, sehingga mencapai tujuan. Prinsip Layout dapat dibagi menjadi 5 prinsip, Proporsi, Keseimbangan, Kontras, Irama, Kesatuan

\section{Tipografi}

Pada buku Tipografi yang ditulis oleh Danton Sihombing (2001:3), tipografi merupakan salah satu pengetahuan disiplin seni mengenai huruf. Huruf merupakan bagian terkecil dari struktur bahasa tulis dan merupakan elemen dasar untuk membangun kata atau kalimat. 7 Pemilihan jenis huruf dan ukuran hendaknya disesuaikan dengan tema/konsep desain. Dan perlu diperhatikan pula bahwa jenis huruf yang berbeda mempunyai ukuran yang berbeda walaupun menggunakan satuan ukuran yang sama (point). Sebaiknya ukuran untuk dalam isi teks atau naskah berkisar $9-12$ point. Font yang digunakan adalah jenis font sans serif karena jenis font ini tidak memiliki kaki dan sirip dengan ketebalan yang hamper sama sehingga menimbulkan kesan modern dan kontemporer.

\section{Desain Komunikasi Visual}

Desain komunikasi visual memiliki tiga makna yang saling berkaitan. Desain berkaitan dengan perancangan estetika, rasa, cita, rasa, serta kreativitas. Komunikasi merupakan ilmu yang menyampaikan maupun sarana untuk menyampaikan pesan. Sedangkan visual merupakan sesuatu yang dapat dilihat. (Kusrianto, 2007: 12) Desain komunikasi merupakan suatu disiplin ilmu yang mempelajari konsep-konsep komunikasi serta ungkapan kreatif melalui berbagai media untuk menyampaikan pesan dan gagasan secara visual dengan mengelola elemen-elemen grafis yang berupa bentuk dan gambar, tatanan huruf, serta komposisi, warna serta Layout (tata letak atau 
perwajahan). Dengan demikian, gagasan bisa diterima oleh orang atau kelompok yang menjadi sasaran penerima (Kusrianto, 2007:2).

\section{METODE PENELITIAN}

Penelitian ini melakukan penelitian dengan menggunakan jenis kualitatif. Menurut Moleong (2005:6) mengemukakan metode penelitian kualitatif adalah suatu riset yang bermaksud untuk memahami fenomena yang dialami oleh subjek penelitian. Metode penelitian adalah untuk mendapatkan data, informasi, mengolah serta menganalisis sekaligus untuk menyusun penelitian dengan beberapa langkah.

Dan pendekatan penelitian menurut Saryono (2010), penelitian kualitatif merupakan penelitian yang di gunakan untuk menyelidiki, menggambarkan, menjelaskan, menemukan kualitas atau keistimewaan dari pengaruh sosial yang tidak dapat dijelaskan, di ukur atau digambarkan melalui pendekatan kuantitatif.

Pengumpulan data dalam penelitian ini menggunakan sumber data sekunder, data sekunder adalah sumber data yang diperoleh dari buku, web, artikel dan seterusnya, yang berkaitan dengan Nyi Roro Kidul. Data sekunder ini digunakan untuk perbandingan dan memperkaya data penelitian teknik pengumpulan data dalam rangka pengumpulan data yang diperlukan dalam penelitian, maka terlebih dahulu perlu dilakukan identifikasi cara pengumpulannya.

\section{HASIL DAN PEMBAHASAN Data Perancangan}

\section{Objek Penelitian}

Buku cerita bergambar ini yang mengangkat cerita asal usul Nyi Roro Kidul banyak diangkat terutama dalam kumpulan cerita rakyat selain itu juga terdapat dalam buku Babad Tanah Jawi yang merupakan karya sastra sejarah berbentuk tembang Jawa. Karya tentang visualisasi dari Nyi Roro Kidul ini banyak diangkat dalam bentuk lukisan, salah satunya yang terkenal adalah karya Basuki Abdullah. Penggambaran sosok Nyi Roro Kidul yang mengenakan busana berwarna hijau dengan aksesoris kalung memberi kesan mewah dan anggun. Penggambaran Nyi Roro Kidul dengan rambut yang terurai berbeda dengan lukisan-lukisan serupa yang menggunakan mahkota emas khas jawa. Dalam perancangan buku cerita bergambar ini kami merancang dengan gaya desain modern dan penggunaan warna CMYK (cyan-magenta-yellow-black) supaya anak-anak tertarik akan buku cerita bergambar tersebut karena menarik akan visualnya. Pemanfaatan pada tokoh tampak pada pelukisan tokoh, jumlah tokoh dan kualitas tokoh. Pelukisan tokoh cerita dilakukan dengan memberikan deskripsi, uraian atau penjelasan secara langsung. Tokoh yang dihadirkan oleh pengarang tidak berbelit-belit, melainkan begitu saja dan langsung disertai deskripsi. Cerita Nyi Roro Kidul terlihat dari struktur narasi, sudut pandang tokoh dan peristiwa sebagai suatu cara narator dikisahkan berjarak dengan pembaca dan tergantung pada penutur karena ceritanya termasuk kedalam cerita tradisional, namun ketika digambarkan menjadi sebuah buku cerita bergambar mengalami modifikasi terlihat dari dikembangkannya cerita.

\section{Konsep Kreatif}

\section{Pendekatan Kreatif}

1. What (Apa)

Apa yang akan disampaikan, yang disampaikan dalam buku ini adalah informasi tentang Nyi Roro Kidul sang penguasa laut selatan, yaitu dengan menceritakan tentang asal mula Nyi Roro Kidul.

2. Who (siapa)

Siapakah target audience terhadap perancangan buku ini. Target buku ini ialah anak-anak usia 05-10 tahun.

3. Where (dimana) 
Dimanakah permasalahan terjadi dan dimanakah buku ini akan dipublikasikan. Ilustrasi dan layout yang dirancang untuk remaja dan orang tua agar tidak bosan saat membacanya perancang memberikan warna color full dalam buku informasi ini.

4. When (kapan)

Buku ini akan dipublikasi ketika sudah lulus sensor dari penerbit.

5. Why (kenapa)

Kenapa adanya perancangan ilustrasi dan layout untuk buku cerita bergambar ini. Dengan adanya perancangan ilustrasi dan layout dikarenakan agar materi atau informasi yang disampaikan mudah dimengerti.

6. How (bagaimana)

Bagaimana buku ini di desain agar sesuai dengan target audience. Dari penjelasan di atas, dapat disimpulkan bahwa cara pendekatan yang digunakan adalah $5 \mathrm{~W} 1 \mathrm{H}$ yang mampu mengidentifikasi masalah serta pemecahannya secara tepat dan sesuai dengan tujuan perancangan buku cerita bergambar tersebut.

\section{Strategi Media}

\section{Karakteristik Target Audience Target}

1. Demografis: Membidik anak-anak yang ingin mengenal tentang cerita Nyi Roro Kidul sang penguasa lautan dan orang tua yang mempunyai balita yang ingin memberikan cerita dongeng kepada anak-anaknya.

2. Psikologis: para orang tua yang ingin menambah pengetahuan tentang Nyi Roro Kidul dan menceritakan pada anak-anak tentang dongeng Nyi Roro Kidul.

3. Behavioristik: Target audiens yang pertama dituju dalam perancangan buku cerita bergambar kisah Nyi Roro Kidul sang penguasa lautan sebagai media ilmu pengetahuan adalah anakanak yang ingin menambah ilmu pengetahuan, setelah menganalisis target audience, perancang menyimpulkan bahwa media yang efektif ialah media cetak yaitu buku.

4. Geografis: Berada di wilayah Jabodetabek, yaitu anak-anak usia 5- 10 tahun dan orang tua yang memiliki anak dan ingin menceritakan kisah Nyi Roro Kidul sang pengusaha laut. Sehingga melalui buku ini, orang tua yang memiliki anak dapat mengetahui dan menjadi pengetahuan untuk para orang dan menjadi suatu kegiatan yang mendekatkan antara orang tua dan anak.

\section{Konsep Kreatif}

\section{Tujuan Kreatif}

1. Tujuan perancangan buku ini adalah untuk menambah pengetahuan pada anak-anak tentang nilai moral yang terkandung dalam cerita rakyat tersebut.

2. Rancangan dapat menyampaikan pesan atau informasi secara persuasif.

3. Rancangan yang divisualisasikan dapat menarik perhatian masyarakat terutama target sasaran.

4. Perancangan dilakukan agar dapat memotivasi keinginan masyarakat untuk mengetahui sejarah asal usul Nyi Roro Kidul sebagai penguasa laut selatan.

5. Desain yang digambarkan dalam cerita tersebut reformasi Nyi Roro Kidul versi modern.

\section{Perancangan Visual}

\section{Isi Buku}

Tema yang diangkat menyangkut tentang pengenalan tentang Nyi Roro Kidul. Perancangan buku ini bersifat persuasif dan menarik ,karena menampilkan ilustrasi yang mudah dipahami dengan memberikan penjelasan lebih rinci dengan menggunakan teks/tulisan, agar audience lebih tertarik dalam membacanya buku ini di buat lebih color full (banyak warna) dan setiap 
halamannya kami buat dengan warna yang berbeda-beda agar terlihat kesan yang berbeda di setiap halamannya.

\section{Ilustrasi}

Layout Gambar dan ilustrasi yang digunakan dalam perancangan buku cerita bergambar Nyi Roro Kidul ini ialah ilustrasi dan Layout yang berkaitan dengan data Nyi Roro Kidul tersebut. Dan juga dalam perancangan ilustrasi dan Layout menonjolkan kesan ilustrasi digital painting dan vector, gambar dan ilustrasi tersebut ditujukan untuk menunjang informasi dan desain layout yang diinformasikan.

\section{Tipografi}

Dalam Perancangan ilustrasi dan layout buku cerita bergambar Nyi Roro Kidul ini jenis font yang digunakan adalah Lemon Juice dimana bentuk huruf tersebut jelas dan mudah dibaca namun tetap menarik sehingga informasi yang disampaikan pun dapat tercapai secara efektif dan komunikatif.

\section{Warna}

Warna-warna yang dipakai dalam desain buku cerita bergambar ini adalah color full. Metode warna yang digunakan pada perancangan menggunakan metode warna CMYK (Cyan, Magenta, Yellow, Key). Dengan melakukan pendekatan perancangan ilustrasi dan layout buku ini menggunakan color full untuk ilustrasi, font, serta background atau latar belakang kertas, sehingga terlihat menarik dan terkesan tidak membosankan.

\section{Komputerisasi}

Dalam perancangan buku cerita bergambar Nyi Roro Kidul ini, Penulis menggunakan software computer Adobe Ilustrator CS6 dalam penataan ilustrasi dan proses layout. Supaya ilustrasi dan Layout yang dirancang memiliki tampilan yang menarik baik itu komposisi dan tipografinya sehingga mudah dibaca oleh audiens.

\section{Hasil Perancangan Buku Cerita Bergambar:}

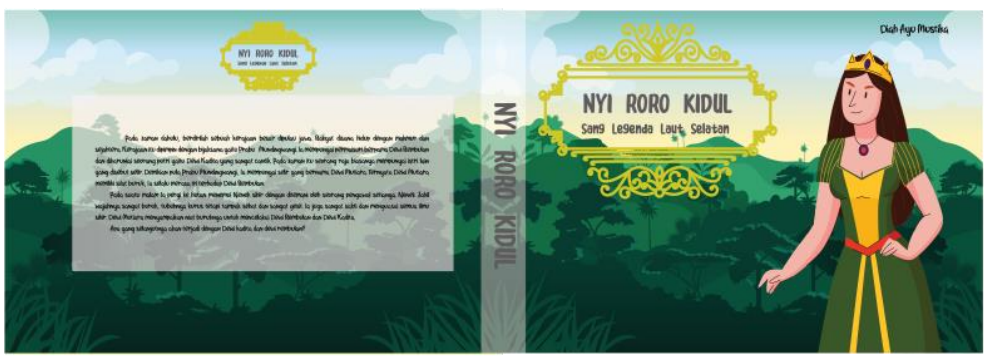

Gambar 1. Cover Buku Cerita Bergambar

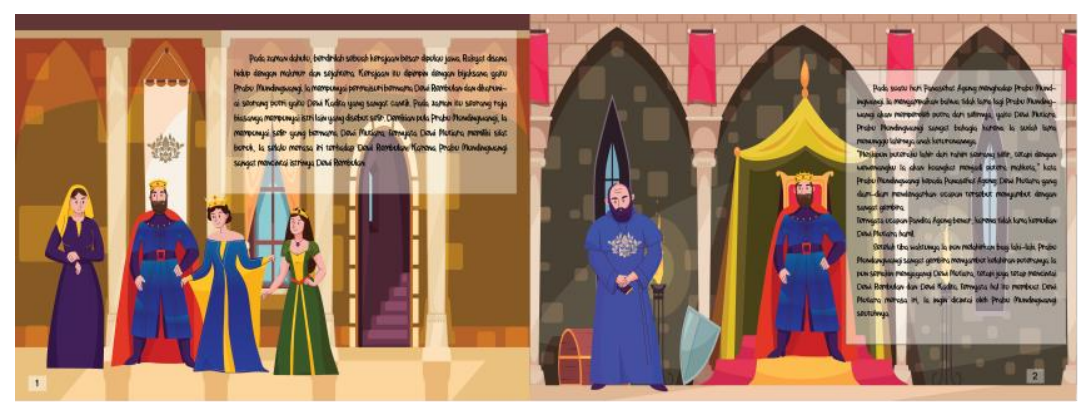

Gambar 2. Isi Buku Cerita Bergambar 

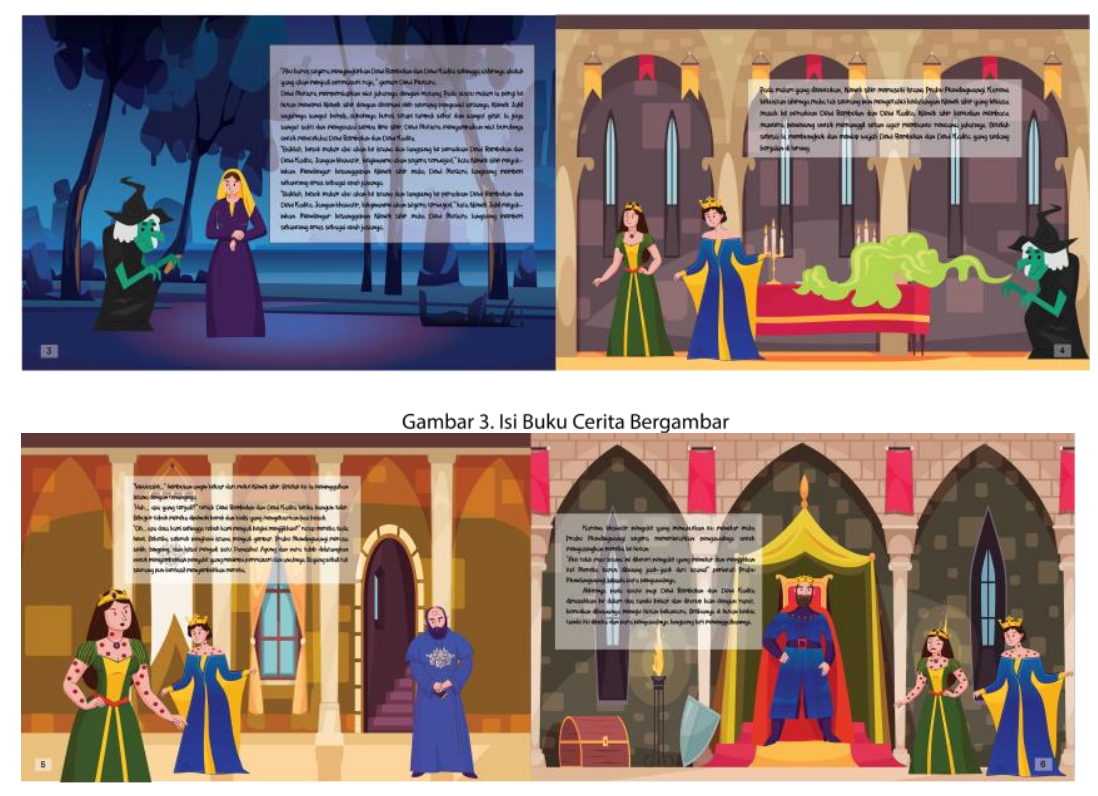

Gambar 4. Isi Buku Cerita Bergambar

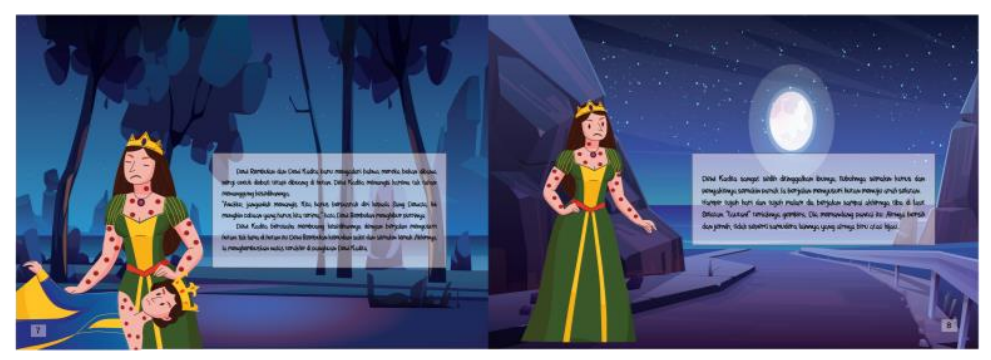

Gambar 5. Isi Buku Cerita Bergambar

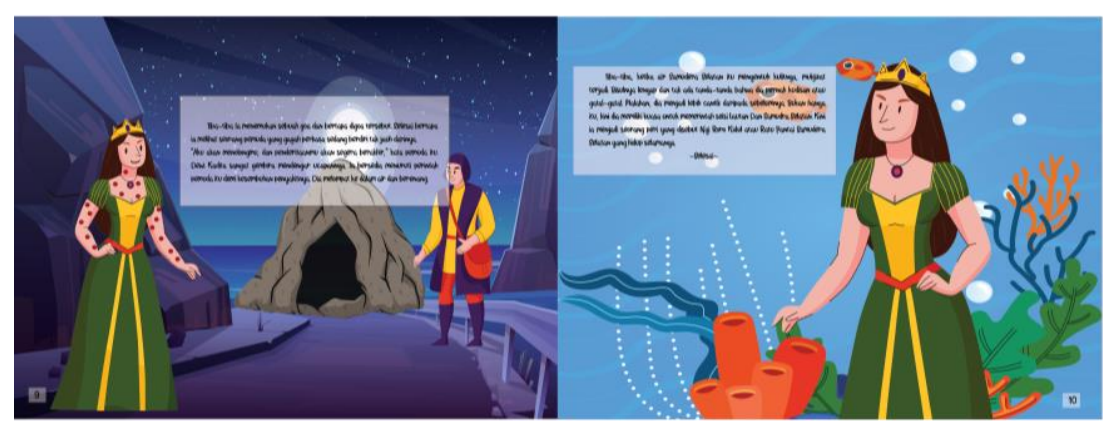

Gambar 6. Isi Buku Cerita Bergambar 


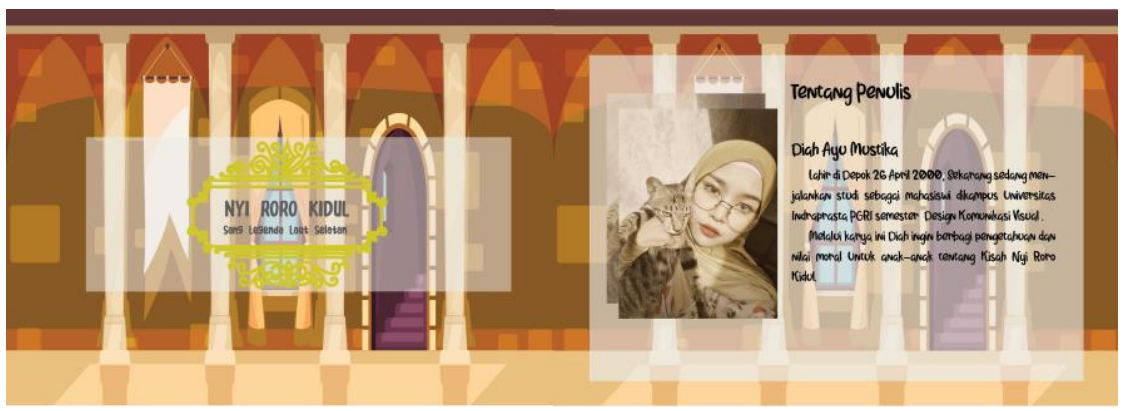

Gambar 7. Halaman Awal Buku Cerita Bergambar

\section{SIMPULAN}

Media buku cerita bergambar ini diharapkan dapat menjadi ilmu pengetahuan bagi para pembacanya. Buku ini di desain dengan cerita yang ringan dan memiliki gambar visual yang menarik, sehingga diharapkan para pembaca dapat memahami cerita Nyi Roro Kidul sang penguasa laut ini dengan mudah. Buku juga dapat menjadi cara para orang tua untuk memberikan dongeng untuk para anak- anak, dengan begitu dapat menjadi suatu kegiatan yang mendekatkan hubungan antara orang tua dengan anak. Dalam perancangan media yang dibuat menggunakan desain karakter yang lebih modern dan jenis pewarnaan CMYK serta gaya ilustrasi yang menggambar sosok Nyir Roro Kidul dengan pengayaan yang ringan dengan menampilkan latar yang menarik sehingga anak-anak dengan mudah mencerna isi dari buku cerita bergambar tersebut.

\section{DAFTAR PUSTAKA}

Agustino, E., \& Yudani, H. D. (2015). Perancangan buku fotografi fashion dengan adaptasi cerita Nyi Roro Kidul. Jurnal DKV Adiwarna, 1(6), 12.

Andari, S., Noorman, S., \& Muhtadin, T. (2016). Mitos Nyai Roro Kidul dalam Novel Sang Nyai. Al-Tsaqafa: Jurnal Ilmiah Peradaban Islam, 13(02), 263-282.

Andayani, A., \& Jupriono, J. (2019). Representation of Nyi Roro Kidul in myth, legend, and popular culture. ANAPHORA: Journal of Language, Literary and Cultural Studies, 2(1), 28-36.

PUTRA, F. W., Heldi, I. D., \& Trinanda, R. (2018). Perancangan buku cerita bergambar Puti Sari Banilai Kabupaten Limapuluh Kota. DEKAVE: Jurnal Desain Komunikasi Visual, 7(2).

Rahayu, Y. (2016). Kearifan Lokal Pantai Laut Selatan (Mitos Nyi Roro Kidul) sebagai Desa Wisata dan Asset Kabupaten Sukabumi. Media Wisata, 14(2).

Santoso, H. (2008). Membangun minat baca anak usia dini melalui penyediaan buku bergambar. Makalah, UPT Perpustakaan Universitas Negeri malang. Diakses dari digilib.um.ac.id

Setiawan, I. (2009). Mitos Nyi Roro Kidul dalam kehidupan masyarakat Cianjur Selatan. Patanjala, 1(2), 188-200. 
Wessing, R. (1997). Nyai Roro Kidul in Puger: Local applications of a myth. Archipel, 53(1), $97-$ 120.

Wessing, R. (2006). Homo narrans in East Java: Regional myths and local concerns. Asian folklore studies, 45-68.

Wiyatmi, W. (2019). When women are as guardians of nature: Reading ideology of ecofeminism in Indonesian folklores. In Proceeding of The International Conference on Literature (Vol. 1, No. 1, pp. 379-391). 